\title{
The Effect of Using Exchange Audible Ball Towards Football Gameplay for Children with Visual Impairment in Surabaya
}

\author{
Saif A. A. Sadewo ${ }^{1, *}$ Sri J. Andajani ${ }^{1}$ Murtadlo $^{1}$ \\ ${ }^{1}$ Universitas Negeri Surabaya, Surabaya, Indonesia. \\ *Corresponding author. Email: saifaliakbarsadewo@gmail.com
}

\begin{abstract}
Children with visual impairment have extremely complicated developmental issues that affect their vision, social interaction, emotions, and movement. They require unique tools and approaches for improving communication and football abilities, particularly in-game skills. One technique is to test and practice. This study was carried out utilizing the Single Subject Research technique using an A-B-A design. The data was collected over the course of 16 sessions. The findings of this study demonstrated the effect of employing an audible exchange ball in football playtime for children with vision impairment in Surabaya Surabaya. This was demonstrated with a 0\% overlap percentage.
\end{abstract}

Keywords: Children with visual impairment, Audible ball method, Football ability.

\section{INTRODUCTION}

Children with special needs are children with unique characteristics different from children in general, such as showing incompetence in mental, emotional or physical conditions. Children with special needs are commonly called Extraordinary Children. According to Mangunsong, an extraordinary child is a child who is significantly different in several critical dimensions of his humanitarian function [1]. In line with the statement, Efendi concluded that a child or extraordinary child is a child who has abnormalities or deviations from the average normal child in physical, mental, and social aspects, so for the development of his potential needs, special educational screens following his characteristics [2].

Education Special physical is an educational service specially designed to meet the needs of persons with disabilities individually and developed to provide physical education services according to individual needs. Children with visually impaired can learn things using mobility orientation techniques than visual or reading written rules in books. One method of orientation that can help visually impaired children in sports football is by field tests and practice directly, and using audible ball media. Audible ball media is one of the media used to develop the sport of football of visually impaired children, namely, by practising football individually or in groups with some of the same visual impairment.

Efforts to develop the ability to play soccer by training children to play the ball continue to be done. Soccer skills are indeed essential, but more important is the understanding of the game and the ability of soccer techniques. The ability to play soccer of visually impaired children can be developed because they still have the potential for mobility orientation, such as through hearing or verbal.

Football is a sport of many choices that are famous globally, including in the territory of Indonesia, and in the sport of football, there are many enthusiasts to do this sport. Football is a simple game, and the secret of a good football game is to do the simplest thing [3]. The popular sport that is football can attract interest for the young to the old, various levels of society, both in terms of male and female genres.

Football learning for visually impaired children is modified in terms of ball media. The use of ball media called audible ball is a three-dimensional medium in the shape of a ball that on the ball gets several holes, and in the ball, some bells can ring when kicked in line with opinions, is a prop that has a length, width and height. If explained, the meaning of three-dimensional learning media, namely media whose appearance can be 
observed from any direction and has dimensions of length, width, and height / thick [4].

According to Lhaksana, the dribbling technique is an essential and absolute skill every futsal player should have [5]. Ability Dribble or dribbling is needed by a player in facing certain situations and conditions that demand an element of agility in moving to control the ball and pass opponents and avoid Collisions that may occur when the opponent wants to seize the ball. In addition, dribbles are used to pass players and can open up space. To create goal-scoring opportunities. By Salim, dribbling (dribble) is keeping the ball on its feet and feet stay in control; when passing, opponents use both sides of the foot to carry the ball or slow the ball's speed by using the sole of the shoe [6]. Dribbling is not just a matter of speed because one would have to change speed and direction.

Azwandi states that an audible ball is one learning tool that accommodates vision limitations in visually impaired by voice or hearing [7]. So that it can be concluded that the development of audible ball can be is defined as a way of advancing, making forward, or adding either audible ball explicitly used by visually impaired students. In this study, researchers used the ball media by being implemented when doing footballthemed sports learning because there will be synchronization between the audible ball media with the play of visually impaired children.

The purpose of this is to implement audible ball media products to improve tested games of visually impaired student football feasibility of the validity aspect of the product.

\section{METHODS}

\subsection{Type of Single-Subject Research}

The method used in this study is an experimental method with the design of Single-Subject Research (SSR), which is research conducted on one subject repeatedly for a certain period.

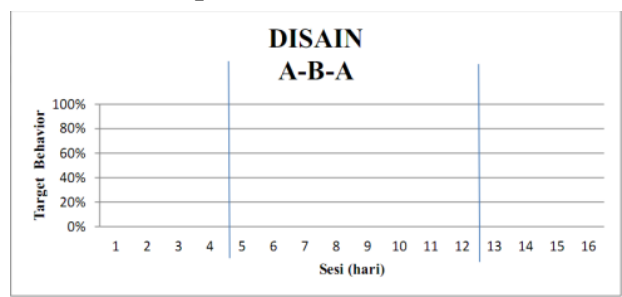

Figure 1 Single-subject research.

Information:

1. A1: At baseline-1(A1), data is collected for at

least 3. Alternatively, five sessions until the data trend become stable.

2. B: After the trend data table, continue research by providing interventions in the condition of intervention
(B) for a certain period until the data trend becomes stable

3. A2: After the trend and data level on the intervention condition, (B) is a stable repeat at baseline-2 (A2) conditions

\subsubsection{Research Subjects}

The subjects in this study were visual impairment students of junior high school, totalling one student assisted by nine children as a comparison on the implementation of audible ball media.

\subsubsection{Data Analysis Techniques}

The data that has been collected is then analyzed with calculations that can be accounted for scientifically. This calculation is done by analyzing the data of each condition and between conditions in studies with a single subject using simple descriptive statistics [8]. The purpose of data analysis in behaviour modification is to see the extent of the effect of interventions on behaviours that want to be changed or target behaviour. The visual analysis method used is to use direct observation of the data displayed in the visual analysis graph. In the process of data analysis on the research of a single subject, many present the data in the graph. This study used two analyses, namely, analysis in conditions and also analysis between conditions.

\subsection{Analysis Under Conditions}

\subsubsection{Length of Condition}

The length of the condition is the amount of data in the condition that also describes the number of sessions in that condition. Sunanto et al. said that the support of conditions is seen from the number of data points or scores in each condition [8]. How much data points depend on the research and intervention issues provided.

\subsubsection{Directional Tendencies}

The direction trend is described by a straight line that crosses all data in conditions where much data is above and below the same line. The ingenuity of the direction of data on a graph is significant to provide an overview of the behaviour of the subject being studied [8].

\subsubsection{Level Stability}

Displays the level of homogeneity of the data under a given situation. The quantity of data in the range of $50 \%$ above and below the mean may be computed and determined to measure the level of stability. 


\subsubsection{Level of Change (Level Change)}

The rate of change indicates the magnitude of the change in data between two data. The rate of change is the difference between the first data and the last date. How to calculate it by determining the first and last few data points (scores) in a condition, reducing the big data with small data, lastly determining whether there is a difference or as described by the formula: Stable percentage $=$ largest data- small data.

\subsubsection{Data Trail}

Data traces are changes from one data to another into a condition with three possibilities, namely, increasing $(+)$, decreasing $(-)$, and parallel to the $\mathrm{x}$-axis or horizontal (").

\subsubsection{Determine The Level of Stability and Range}

The range is the distance between the first data and the last date. The level of stability indicates the degree of variation or magnitude of the range in a given data group. If the data range is small or the variation is low, then the data is stable. To determine the level of stability and range is to determine the average level done by summing the value of all data points and dividing the amount of data by the number of data points. In general, the data is said to be stable when it reaches $80 \%-90 \%$, while below it is said to be unstable (variable).

\subsection{Analysis between Conditions}

It is very influential in explaining the effect of interventions on bound variables. Sunanto et al. argue that the analysis of changes between stable data conditions must precede the conditions to be analyzed [8]. The components in the analysis between conditions are:

1. Changed variables.

It is a bound variable or focused goal.

2. Changes in direction and effect.

It is the ingenuity of the graph's direction between the condition of the baseline and the intervention.

3. Changes instability and their effects.

Data stability indicates the stability of changes from a series of data.

4. Data level changes.

It shows how much data has been changed

5. Overlapping data.

Overlapping data between two conditions occur as a result of the same data state on both conditions.
The steps taken in analyzing these data are:

1. Assessing the results of the assessment on baseline condition 1 (A-1)

2. Resulting in interventional conditions (B)

3 . Assessing the results of the assessment on the condition of baseline 2 (A-2)

4. Create a research table for scores that have been obtained on baseline condition 1, intervention condition and baseline 2 .

5. Comparing the results of the score on baseline 1 , intervention score and baseline 2 .

6 . Analyze the line graph shape data to see the changes that occur from all three phases directly.

Make an analysis in conditions and between conditions.

\section{RESULTS AND DISCUSSION}

\subsection{Results}

The first step in data retrieval is to assess the individuals' initial football ability before they get intervention. From March 16, 2020 through June 29, 2020, baseline-1 (A1) conditions were measured. Measurements are taken across four sessions, each lasting 45 minutes.

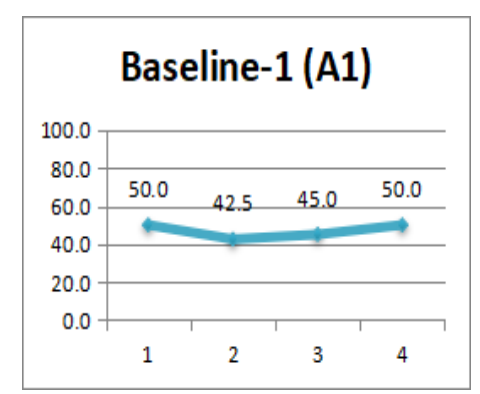

Figure 2 Baseline condition measurement results- 1

(A1) ability to play ball of visually impaired children.

The assessment findings of baseline condition-1 (A1) ability of visually impaired football players class VII junior high school YPAB Surabaya are displayed with a blue line graph in Figure data 4.1. The figure above depicts the greatest percentage $(50 \%)$ in the fourth session and the lowest percentage $(45.0 \%)$ in the third session. The image depicts the capacity to play the ball prior to receiving therapy or intervention. Documentation of the execution of baseline-1 (A1) condition measurement of visually impaired children in Surabaya Surabaya is provided below.

Measurements on intervention conditions (B) were taken from April 13, 2020, to May 18, 2020. This condition is done for eight sessions with a period of 45 minutes/session. In the interventional condition (B), the child receives the intervention. These measurements 
were taken after subjects received an intervention playing football.

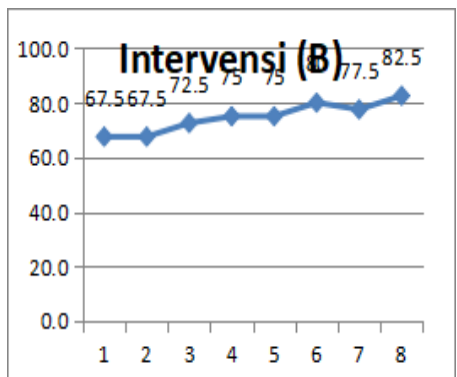

Figure 3 Results of measurement of intervention conditions (b) ability to play ball of visually impaired children.

Graph 4.2 data shows the results of intervention measurement (B) football skills of visually impaired children class VII junior high school YPAB depicted with a blue line graph. The graph above shows the highest percentage getting a percentage of $80.0 \%$ in the 6th session and the 8th session. The lowest percentage in this condition is $67.5 \%$ in the 1 st session. The graph illustrates a child's footballing abilities when given treatment or intervention.

Measurements on baseline-2 (A2) conditions were taken from May 25, 2020, to June 15, 2020. This condition is done for four sessions with a period of 45 minutes/session. In baseline-2 (A2), the subject is not given any intervention at all. This condition is used to evaluate how influential the interventions the researchers have exerted on the subject are.

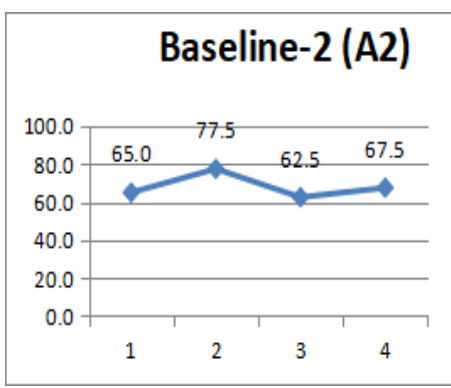

Figure 4 Results of baseline-2 condition measurement (A2) football ability of visually impaired children.

Graph data 4.3 shows the results of measuring the condition of baseline-2 (A2) football ability of visually impaired children grade 1 SMPLB depicted with a blue line graph. The graph above shows the highest percentage getting a percentage of $77.5 \%$ in the 2 nd session. The lowest percentage in this condition is $65.0 \%$ in the 1 st session. The graph illustrates a child's soccer-playing ability after being given treatment or intervention.
Table 1. Measurement recapitulation results ability to play ball of blind children in Junior High School YPAB Surabaya

\begin{tabular}{|c|c|c|}
\hline Session & Condition & Result \\
\hline 1 & & $50,0 \%$ \\
\hline 2 & & $42,5 \%$ \\
\hline 3 & $\mathrm{~A} 1$ & $45,5 \%$ \\
\hline 4 & & $50,0 \%$ \\
\hline 5 & & $67,5 \%$ \\
\hline 6 & & $67,5 \%$ \\
\hline 7 & & $72,5 \%$ \\
\hline 8 & $\mathrm{~B}$ & $75,0 \%$ \\
\hline 9 & & $75,0 \%$ \\
\hline 10 & & $80,0 \%$ \\
\hline 11 & & $77,5 \%$ \\
\hline 12 & & $82,5 \%$ \\
\hline 13 & & $67,50 \%$ \\
\hline 14 & $\mathrm{~A} 2$ & $70,00 \%$ \\
\hline 15 & & $65,00 \%$ \\
\hline 16 & & $70,00 \%$ \\
\hline
\end{tabular}

\subsection{Discussion}

The capacity to communicate prior to intervention B in the form of testing and practice of playing football utilizing audible ball media is considerably lower. In this state, the youngster still has difficulties understanding the game. The rules and tactics for playing the ball are still quite limited. In addition, youngsters have trouble identifying football playing methods. Students sometimes misinterpret the communicator's request that the youngster kick the ball towards him. When children are given different balls, they often grasp the wrong one.

In this condition, the average score gained from the ability to play football (mean level) by $50.00 \%$ with an estimated tendency to level the direction, but the range of acquisition of the score of the ability to play the ball blind is low. Thus, the increase in the score is not striking. The tendency of stability in the baseline-1 phase towards the ability to play football shows a $100 \%$ figure which means the data is stable. In addition, the data footprint of ball-playing ability in the baseline-1 phase is flat because the initial data score and the last data score in the baseline-1 phase are similar, but the increase in the range of scores obtained is low.

The amount of change in the ability to play the ball in the baseline- 1 phase displays a score $=0$, indicating that there is no change since the score gained on the first day was 50.00 percent, and the score received on the last day was similarly 50.00 percent. Thus, based on the 
data analysis, it can be stated that the study's results in the baseline phase- 1 demonstrated that the football skill of visually impaired children remained poor, indicating that participants still need intervention to increase their ability to play football.

In "Sound Localisation", this technique, sound does not only determine the distance or distance of the object since it is vital for visually impaired people. With instructions from sound, children can learn quickly to know the localization of objects in the blind area; an example of knowing a sound ejected from the object can be a sign for the child of what object is within its reach. Therefore in visually impaired children, one of the senses that only hearing can be maximized in this sport.

The results on intervention conditions (B) showed an increase, the calculation of data analysis showed it in conditions of intervention conditions (B) with a mean level of $77.5 \%$, the condition of the estimation of increasing directional tendencies, the estimated trace of data that increased because the score obtained was stable and increased. The change level showed positive (+) of +12.5 , which means the subjects experienced an increase in the ability to perform football techniques.

After being given intervention, the condition of baseline-2 (A2); this condition is done to find out how much influence intervention (B) has on the study subjects, or this condition can be called a control condition. Changes in conditions from interventional conditions (B) to baseline-2 (A2) conditions decreased. However, the score obtained increased in the final baseline condition (A2) compared to the initial baseline condition (A1). This is indicated by the acquisition of a mean level score of $75.0 \%$. In addition, the condition of the estimated tendency of the direction of the baseline-2 phase (A2) showed an increase when compared to baseline-1 (A1), the estimated data footprint increased because the score of the football obtained stably increased, and the level of change showed +7.50 which means the subjects experienced an increase in football ability by $7.50 \%$.

Ability in the game of football increases when given intervention using tests and practices. As well as doing the practice of playing the Ball kicking, dribbling, and passing, responding to instructions when the child is asked to kick and pass the ball, able to make passes that lead to an instruction seen a change in the average test value and practice $42.5 \%$ before being given an intervention by using tests and practices to $70.0 \%$ on the average post-test or after being given intervention.

Research on the influence of audible ball media on the ability to play the ball of visually impaired children in YPAB Surabaya Junior High School shows that the tests and practices of football used can improve the ability to play visually impaired children. This state indicates the score of football ability at baseline-1 (A1) ranges from $42.5 \%$ to $50.0 \%$. Meanwhile, a significant increase in scores was shown during the intervention conditions (B) of $75.0 \%$ to $82.5 \%$, then for the baseline control phase-2 (A2), the score of ball-playing ability to $65.0 \%$ to $77.5 \%$. The change in the level of the intervention condition (B) to baseline-1 (A1) of +20.00 means that there is an increase in the score from baseline-1 (A1) to intervention (B). In the results of this study, overlap intervention to baseline-1 (A1) showed a result of $0 \%$ means that interventions that are tests and practices using audible ball media have a good influence on the ability to play soccer of visually impaired children.

\section{CONCLUSION}

The ability to play football before being given intervention is lower than football after being given intervention. After being given intervention using audible ball media, the ability to play football increased compared to the previous baseline condition. Using audible ball media affects the ability to play soccer of visually impaired children. All in all, it can be concluded that the intervention affects the targeted behaviour.

\section{REFERENCES}

[1] F. Mangunsong, Psikologi dan Pendidikan Anak Luar Biasa, Lembaga Pengembangan Sarana Pengukuran dan Pendidikan Psikologi (LPSP3) UI, 2009.

[2] M. Efendi, Pengantar Psikopedagogik Anak Berkelainan, PT Bumi Aksara, 2008.

[3] E. C. Batty, Latihan Sepakbola Metode Baru Serangan., CV Pionir Jaya, 2003.

[4] N. Sudjana, Penilaian Hasil Proses Belajar Mengajar, Rosdikarya, 2006.

[5] J. Lhaksana, Taktik dan Strategi Futsal Modern, Be Champions, 2011.

[6] A. Salim, Buku Pintar Sepak Bola, Nuansa, 2008.

[7] Y. Azwandi, Media Pembelajaran Anak Berkebutuhan Khusus, Depdiknas Dirjen Dikti Direktorat Ketenagaan, 2007.

[8] Sunanto, dkk, Pengantar Penelitian dengan Subyek Tunggal, CRICED University of Tsukuba, 2005. 